\title{
Home on a Transitioning Range: A Ranch Simulation Game Demonstrating STMs
}

\author{
By James Pritchett, Emily Kachergis, Jay Parsons, Maria Fernandez-Gimenez, \\ and John Ritten
}

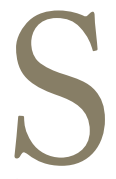

tate-and-transitions models (STMs) are becoming a preferred method for monitoring rangeland ecosystems and a key input in adaptive management strategies. Yet, land managers do not readily adopt these tools. In this article, we suggest a creative means for increasing awareness of STMs through active participation in a ranch management game accompanying an STM workshop. Recent evaluations indicate successful transmission of key concepts, but adoption of STMs will take time to measure. We review the impetus for developing the STM game, describe the workshop/simulation game structure, and conclude with notable limitations and next steps.

\section{The New Approach: STMs and \\ Economic Outcomes}

Have you ever wished that you had a road map to monitor and adaptively manage changes to your rangelands? STMs are conceptual models or "road maps" of ecosystem change based on site-specific information. The utility of STMs is widely recognized among natural resource agencies. In 2010, the USDA Natural Resource Conservation Service, US Forest Service, and Bureau of Land Management signed a memorandum of understanding agreeing that STMs would be the standard basis for rangeland evaluation and monitoring.

Knowledge of ecosystem dynamics is never complete, so STMs represent working hypotheses that are revised as new knowledge is gained through adaptive management. In fact, STMs are an important adaptive management tool-they clearly represent how a given ecosystem responds to different management and environmental factors. As new knowledge is gained through management and monitoring, this information can be used to update STMs. STMs are being coupled with ranch economics to evaluate stocking decisions, forage purchases, and managing lands for wildlife. ${ }^{1}$

As with any rangeland management innovation, a significant gap exists between awareness and application of STMs. In a recent survey of 411 ranchers in several Colorado and
Wyoming counties, Kelley ${ }^{2}$ found that a majority of ranchers had never heard of (69\%) or used (98\%) STMs. Although most of the 312 natural resource professionals surveyed had heard of STMs (76\%), most had never used them (69\%). To the adult learner, STMs can represent new knowledge and a paradigm shift in rangeland monitoring and adaptive management. The challenge is to transfer this knowledgeboth site-specific ecological site descriptions (ESDs) and the broader STM framework - to land managers in a manner that is both engaging and contextually relevant. Our approach is asking adult learners in an extension workshop to "play" at managing a ranch with STMs.

\section{An Innovative Game and STM Workshop}

We create a cooperative learning environment with the S\&T Ranch game, which is a ranch simulation game executed in an Excel workbook. The game is the centerpiece of an STM extension workshop connecting ecological monitoring, economic outcomes, and adaptive management.

\section{Workshop Design}

Workshops are open to the public and advertised via targeted e-mailing. Delivery is best with smaller groups (20 to 30 adults), organized with local direction and input of an extension agent, and comprised of mixed clientele: ranchers, educators, agency personnel, and researchers. Workshop duration is between 3 and 4 hours but can be shortened. The physical location is a standard meeting room, but sufficient space is needed for laptop computers with two to three participants stationed at each computer. These participants are grouped together as a management team. The workshop experience has four distinct phases: i) welcome/introductions; ii) introduction to ESDs and STMs, iii) playing the ranch simulation game and repeating the simulation as time permits, and iv) debriefing the game experience and linking it to the workshop objectives. The introduction, game playing, and debriefing create an experiential learning opportunity. 


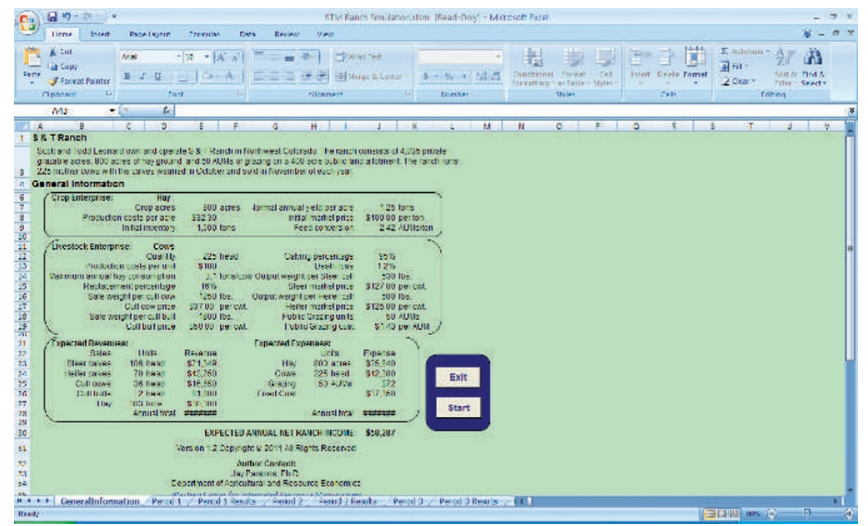

Figure 1. General Information Page of the S\&T Ranch Game.

Significant teachable moments accompany the S\&T Ranch Game, which is described in the next section.

\section{The S\&T Ranch Game}

In the S\&T Ranch game, groups of two to three workshop participants form a management team that must make decisions about stocking rates and herbicide spraying on the S\&T Ranch. Why is a game used when delivering STM knowledge? A game creates an interactive learning environment conducive to producing long-term growth in decisionmaking skills. In the game, management teams must make decisions, and discussions between team members reinforce STM knowledge delivered earlier in the workshop. Perhaps more importantly, team members share their understanding of STM concepts and their previous experience. Comparing game results between management teams incites lively discussion. Workshop participants are typically highly engaged and eager to repeat the experience. The S\&T Ranch game allows individuals to test adaptive management skills firsthand, in a realistic but consequence-free environment. In this way, management teams can experiment with different management strategies and examine the consequences of their decisions.

The S\&T Ranch is a spreadsheet-based computer game centered on a working ranch in northwestern Colorado that is representative in the size of its land holdings, cow herd, economics, and ecological sites. Key indicators include the current profitability of the ranch, the ecological states found on the ranch, the likelihood of transitioning to another state, and provision of ecosystem services. After completing the game, participants should:

- Become more aware of ecological site descriptions and their use;

- Better understand STMs and how they can be used in adaptive management;

- Have an increased familiarity with the tradeoffs between ranch profitability and the provision of ecosystem services in addition to the tradeoffs among ecosystem services; and

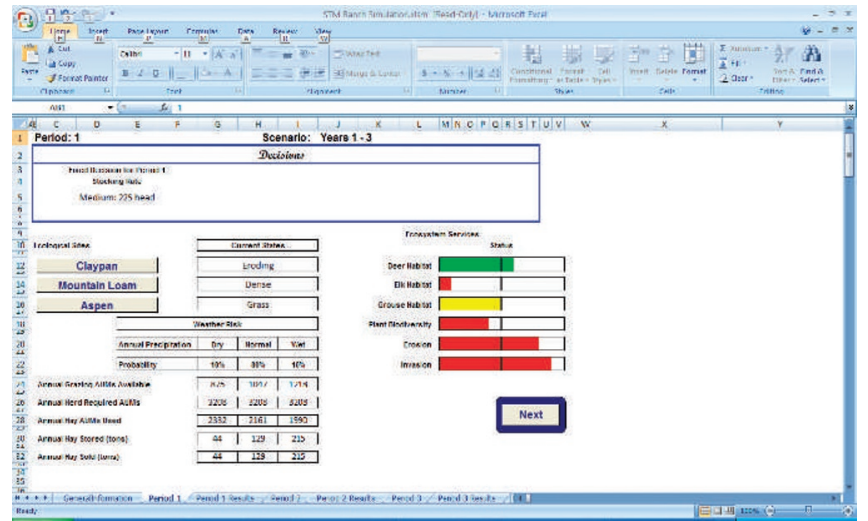

Figure 2. Ecosystem Services Indicator Page.

- Understand the path dependence of transitions - that is, that some states are very hard to transition out of and into another state.

\section{The S\&T Ranch Scenario}

An accurate scenario is important in creating teachable moments. The S\&T Ranch is operated by Scott and Todd Leonard, who manage a 225-cow operation with 4,035 grazeable acres, 800 acres of hay ground, and 50 animal unit months (AUMs) of grazing on a 400-acre public land allotment. Figure 1 is a screenshot of the basic ranch information as it is shown to the player. The ecology of the ranch is simplified for this game, and ecosystem services indicators are provided to players (Fig. 2). The ranch contains three ecological sites prevalent in northwestern Colorado. Each ecological site provides varying amounts of ecosystem services, and these are represented by the stoplight charts at the right hand side of Figure 2, as well as the forage production for cattle on the left hand side. The ecological sites have two, three and four possible states. The states are described using basic monitoring indicators (e.g., forage produced) and a digital picture. (Fig. 3 is an example for the Claypan ecological site). The ecological sites can transition from one state to the next, and the likelihood of transition is described to players in tables (Fig. 3). Several factors can serve as transition triggers, including

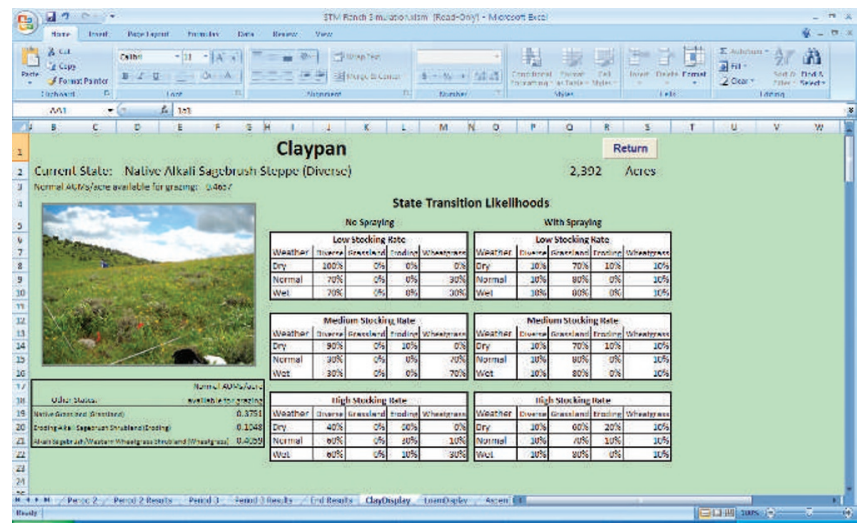

Figure 3. Claypan Ecological Site Description from the S\&T Ranch Game. 
those within the control of the game player (e.g., stocking rate) or beyond their control (e.g., weather).

\section{Behind the Game}

An accurate context for the S\&T Ranch game lends credibility to the workshop outcomes and encourages adoption of STMs. Our S\&T Ranch game is grounded in site-specific ecological and economic research.

The S\&T ranch's land area is based on the proportional makeup of northwestern Colorado's Elkhead watershed and was verified with local ranchers. Basic ranch performance characteristics (e.g., weaning percentage) are sourced from Rowe and Bartlett ${ }^{3}$ as well as FLIPSIM models. ${ }^{4}$ The ranch is comprised of 2,392 acres in the Claypan site, 386 acres in the Aspen site, and 1,057 acres in the Mountain Loam site. The ranch utilizes a fixed amount of public AUMs and has access to 200 acres of riparian area, which provides a total of two AUMs per acre, with livestock able to utilize $35 \%$ of total production.

The STMs used in the game are based on integrated models derived from combinations of qualitative local knowledge and quantitative ecological field data. ${ }^{5,6}$ We developed STMs for three ecological sites that are prevalent in the Elkhead Watershed: Claypan, Mountain Loam, and Aspen. Claypan has clay soils and is characterized by low sagebrush; Mountain Loam has loamy soils and is characterized by mountain big sagebrush; and Aspen has variable soils but is dominated by aspen. ${ }^{7}$ Probabilities of transitions between states were determined through elicitation from experts and combining them in the framework of a Bayesian Belief Network (BBN) for the Claypan and Mountain Loam ecological sites. A dy- namic, stochastic simulation process generates the ranch economic and ecologic outcomes from the data. These results are the data matrix from which the game outcomes are drawn.

Ecosystem service values for each state are based on ecosystem monitoring indicators related to provision of those services. Indicators were averaged across all monitoring plots within a particular state to come up with one value for each state. Forage production was calculated from herbaceous plant production clipped at peak production. Plant diversity was calculated as the average species richness per $1,000 \mathrm{~m}^{2}$ plot. Resistance to invasive plants was determined from the relative percent cover of invasive plants. Resistance to erosion was calculated as the sum of qualitative ratings of erosionrelated Indicators of Rangeland Health. ${ }^{7}$ Wildlife habitat indicators for elk, sage grouse, and mule deer were developed using fuzzy logic quantifying how site-specific habitat attributes meet habitat requirements (cover and forage) according to the literature and expert knowledge. These indicators vary from $0-1$ and are converted to the stoplight graphs displayed in Figure 2.

\section{Playing the S\&T Ranch Game}

Workshop participants play the role of ranch managers making timely decisions about stocking rates and chemical shrub treatment (spraying) over a 9-year period with decisions made in 3-year increments (Fig. 4). The management team discusses their decision among themselves; but not every team need make the same decision during game play. At each decision point, the management team is aware of the current ecological state of the rangeland, as well as the provision of ecosystem services, including sage grouse, deer, and

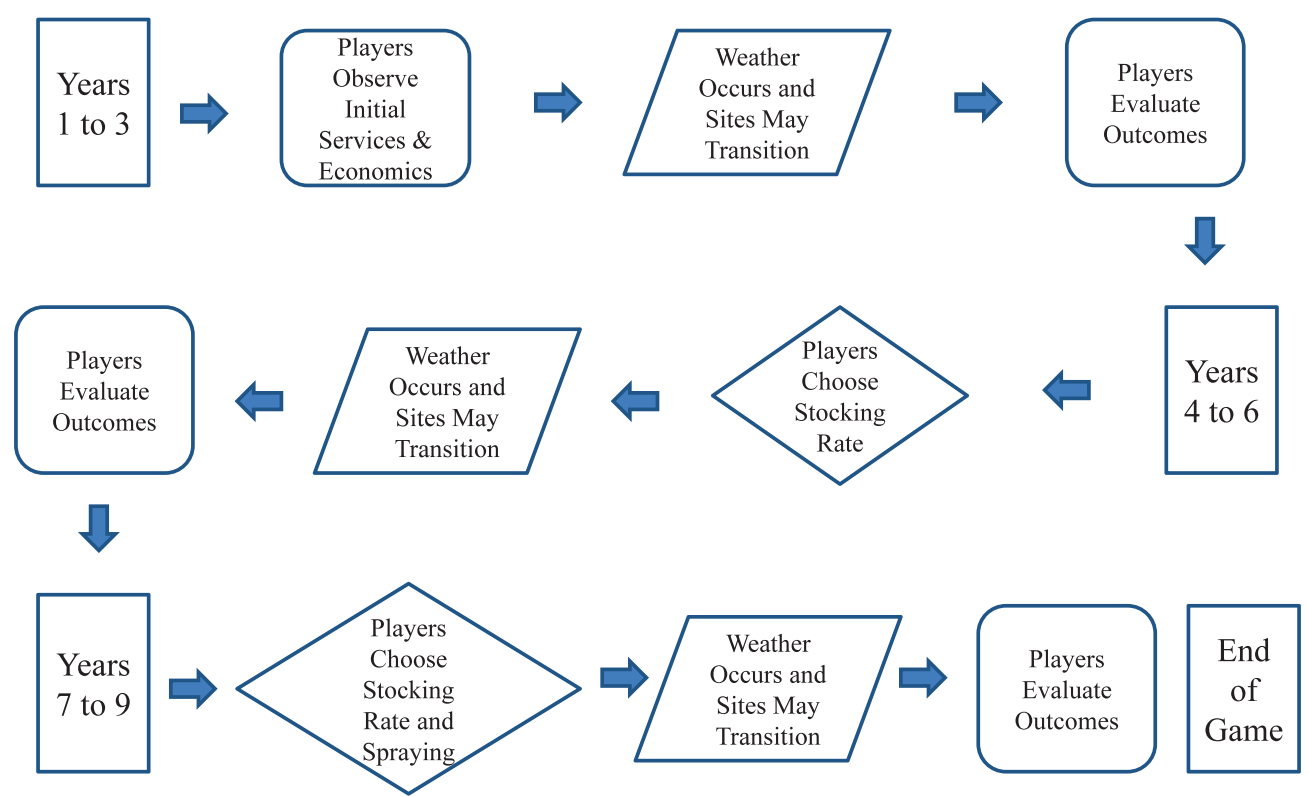

Figure 4. Flow Chart Indicating the Game Decisions Node for the S\&T Ranch Game. 
elk habitat. However, the team only has a probabilistic notion of how ecological sites might transition from one state to the next after their management decision. In between decision points, the ranch experiences a (random) weather event that, depending on previous management decisions, might cause an ecological site to transition to another state. Ranch profits and the provision of ecosystem services are updated (Fig. 5), and then the decision process is repeated. The game is repeated as time permits, but the game period always concludes with significant time devoted to debriefing participants.

\section{Teachable Moments from the S\&T Ranch Game}

The S\&T Ranch game creates opportunities for lively discussions among teams as they interpret the ecological site information, make stocking and spraying decisions, and observe outcomes. Workshop facilitators seize on these conversations to emphasize teaching points related to STMs and economic tradeoffs. In addition to increasing awareness of STMs, the following teaching points are emphasized during the sessions:

- Tradeoffs: Managing the ranch to improve profits can come at a cost, and this cost is potentially manifested as a reduction in ecosystem services. For example, excessive stocking can, but does not always, lead to an undesirable state for subsequent ranch profits and ecosystem services. Likewise, specific ecosystem services do not benefit equally from the same state. For instance, the state(s) preferred for sage grouse habitat might be less desirable for elk habitat.

- Path Dependence: Once an ecological site is in an undesirable state, it can be very difficult and costly, if not impossible, to move to a more desirable state. Moreover, the initial state of the ecological site is critical in determining future outcomes.

- Control: In spite of "good" management decisions, uncontrollable events such as weather can result in an undesirable state. At the same time, poor decisions do not always result in undesirable outcomes. Importantly, managers put themselves in the best position to reach goals by making good decisions, but outcomes are not in the manager's complete control.

As we discuss in the next section, the workshops have been successful in creating teachable moments, and at times, have created unexpected outcomes.

\section{Workshop Outcomes}

Four workshops tested the utility of the S\&T Ranch game as a teaching tool. The first workshop was attended by Colorado State University (CSU) Extension employees as part of their annual meeting on 9 November 2011. The largest proportion of attendees (38\%) was county agents, followed by extension specialists (13\%) and regional agents or directors (13\%). A majority of participants $(75 \%)$ had heard of ecological site descriptions (ESDs).

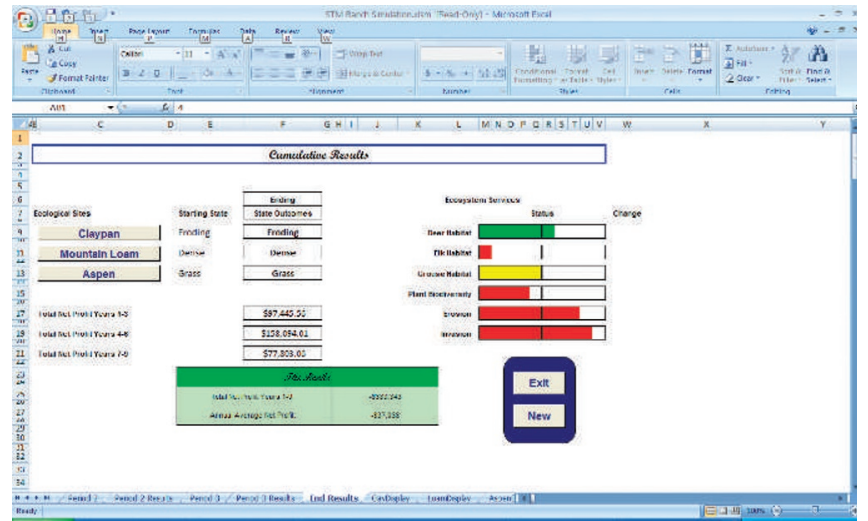

Figure 5. Ecosystem Services and Ranch Economics Outcomes Page.

The second workshop was part of the annual Nick Petry event at the National Western Stock Show, whose theme was "Ranching for Production and Conservation: Synergies and Trade-offs," on 2 December 2011. A diverse audience included integrated resource management graduate students and ranchers/farmers (33\% and 28\%), followed by natural resource professionals (20\%), none of the above (13\%), and business or industry (7\%). A majority of participants were aware of ESDs and STMs (74\% and 61\%, respectively), although many of them did not use them in their work (43\% and $53 \%$, respectively).

The third and fourth workshops were hosted by CSU Extension in two Colorado ranching communities, Hayden and Meeker, on 11 January 2012. Although we did not collect demographic data, based on our observations, the Hayden workshop was a mix of ranchers and natural resource professionals, whereas the Meeker workshop was mostly ranchers. Hayden is also where we collected our quantitative field data ${ }^{5,6}$ with cooperating ranchers, and several workshop attendees participated in that process.

\section{Workshop Assessments}

We evaluated outcomes through a two-page self-assessment of knowledge before and after each workshop (74 self-assessments total: Extension workshop, 6; Nick Petry, 35; Hayden, 18; Meeker, 15). As indicated in Table 1, we asked workshop participants to rate their knowledge of nine different topics as being "Low," "Medium," or "High."

Before each workshop, participants rated themselves lowest in STM knowledge and skills statements such as "Applying state-and-transition models to rangeland management," although ecological site-related ratings were only slightly higher (Table 1). At the Meeker workshop, a majority of participants rated themselves "Low" on both concepts.

After the workshop, participants consistently rated themselves higher in both their understanding of these concepts and their ability to apply them to rangeland management (Table 1). A large segment of participants signaled improvement from the "Low" to the "Medium" knowledge categories. Interestingly, a previous survey identified a gap between the 
Table 1. Participants' self assessment of ecological site description (ESD) and state-and-transition model

(STM) knowledge before and after the workshop

\begin{tabular}{|c|c|c|c|c|}
\hline \multirow[t]{2}{*}{ Knowledge and skills } & & \multicolumn{3}{|c|}{$\begin{array}{l}\text { Number of participants indicating } \\
\text {... }\end{array}$} \\
\hline & & Low & Medium & High \\
\hline \multirow{2}{*}{$\begin{array}{l}\text { Understanding ecological sites and ecological site descriptions } \\
\text { (ESDs) }\end{array}$} & Before & 52 & 30 & 18 \\
\hline & After & 1 & 70 & 28 \\
\hline \multirow{2}{*}{ Applying ecological sites and ESDs to range management } & Before & 61 & 26 & 13 \\
\hline & After & 10 & 64 & 26 \\
\hline \multirow{2}{*}{ Understanding state-and-transition models } & Before & 63 & 25 & 11 \\
\hline & After & 8 & 69 & 23 \\
\hline \multirow{2}{*}{ Interpreting state-and-transition models } & Before & 72 & 19 & 8 \\
\hline & After & 18 & 57 & 25 \\
\hline \multirow{2}{*}{ Applying state-and-transition models to rangeland management } & Before & 71 & 20 & 9 \\
\hline & After & 14 & 59 & 27 \\
\hline \multirow{2}{*}{$\begin{array}{l}\text { Applying state-and-transition models to ranch management deci- } \\
\text { sions }\end{array}$} & Before & 71 & 23 & 6 \\
\hline & After & 13 & 69 & 19 \\
\hline \multirow{2}{*}{$\begin{array}{l}\text { Understanding tradeoffs between managing for different ecosys- } \\
\text { tem services }\end{array}$} & Before & 53 & 37 & 10 \\
\hline & After & 14 & 55 & 32 \\
\hline \multirow{2}{*}{$\begin{array}{l}\text { Applying tradeoffs between ecosystem services and to manage- } \\
\text { ment decisions }\end{array}$} & Before & 59 & 34 & 7 \\
\hline & After & 16 & 62 & 22 \\
\hline \multirow{2}{*}{ Understanding importance of the initial state } & Before & 47 & 36 & 18 \\
\hline & After & 10 & 47 & 44 \\
\hline
\end{tabular}

percentage of respondents who understood ESDs and STMs but who did not use these tools. ${ }^{2}$ In our workshop assessments, participants rated themselves almost equally able to understand as to apply these tools (Table 1), suggesting that this hands-on exercise might help close the gap between understanding of these rangeland management innovations and their implementation.

We used open-ended questions in the assessment to gauge the impact of the workshop. In the assessment, workshop participants were asked, "What will you do differently in your practice/service setting as a result of this training?" Responses focused on a diverse set of factors. Several participants noted that their decision-making context will change to consider time $(n=4)$, weather (2), and ecosystem state (12); or using rangeland management practices differently than they had in the past (overall = 14 ; spraying $=3$; stocking rates $=5$ ). Some commented on how difficult it can be for ecosystems to recover from an undesirable change: "Use the understanding that returning to high quality 'states' may be very difficult and expensive, after you cross the threshold." Several people said they would use ESDs and STMs for rangeland planning (4) and monitoring (2). A few also mentioned that they would look up the ESD website, and be better able to communicate with ranchers and/or federal agency employees about ESDs and STMs.

The self assessments are instructive and indicate that the workshop and S\&T Ranch game increased awareness of STMs. Facilitators observed conversations reinforcing the assessment results, lending credibility to the S\&T Ranch game. During conversations at the workshop, facilitators gleaned the following comments from participants:

- After a workshop session, one rancher told several others that government agency personnel were part of his team. At first the agency personnel wanted to stock very conservatively, but eventually saw that they were losing money, and started to factor both ecology and profitability into decisions. They did well in the game after that. It appears an outcome of the game might be an improved understanding of management perspectives on the part of different stakeholders. 
- In one workshop, three ranchers formed a management team. The ranchers discussed each decision at length, swapping stories of their past experiences far beyond the reach of the game. This management team consistently performed well, lending credibility to the use of local knowledge and the "art" of rangeland management in decision making and the game itself.

- Some scenarios involve very poor weather outcomes. After completing one such scenario, a participant remarked "There was nothing you could've done once the transition [to an Eroding Claypan state] happened." Another remarked "It's simple, ranching is Vegas."

\section{Limitations and Next Steps}

Workshop outcomes indicate the S\&T Ranch game heightens awareness and has the potential to encourage wider adoption of STMs. As demonstrated in earlier comments, game participants learn from each other. Discussions about the game build confidence in using STMs when making decisions. Successful outreach programming hinges on exploiting this type of cooperative learning environment.

However, it's too early to assess actual impacts of the workshop until adoption can be measured. Limitations to this workshop and the S\&T Ranch game include:

- Perverse Outcomes: As mentioned in the Behind the Game section, a stochastic dynamic simulation model generates the outcomes from which the S\&T Ranch game results are drawn. Under favorable climate conditions, high stocking rates might not diminish ecological state - in fact, transitions to a more desirable state might occur. This is an infrequent occurrence that underscores the notion that uncontrollable events play a role in ecosystem health.

- Few Management Tools: Game participants note that, in reality, they have more management options than simply adjusting stocking rates and herbicide spraying. The game has been simplified to create teachable moments, so it is natural that participants see other alternatives for adaptive management. Likewise, the timing of decisions is artificially constrained in the game. In reality, decision makers can adaptively manage throughout a grazing season rather than at its beginning.

- Representativeness: Decision makers would like to tailor the model to match their own rangeland ecology and economic situation. This is an important distinction-the S\&T Ranch model is a teaching tool rather than a forecasting model. Financial and time constraints prevent the creation of tailored S\&T games.

The initial success of the STM workshop and S\&T Ranch game is encouraging. Next steps include transferring the game to college and high school classrooms as part of rangeland ecology and adaptive management curricula. Additional gains can be made by shifting the geographic area from northwestern Colorado to other rangeland systems, and our design team is seeking funding to scale up and transfer this approach to other areas. The workshop is at its best when it can be coupled with on-the-ground demonstration and training in STMs as a means of addressing a gap between STM awareness and STM adoption. Our team is seeking funding for this coupled approach. Lastly, we will repeat a survey after additional workshops to gauge impacts of our efforts on STM adoption.

\section{Where to find the S\&T Simulation Game and Materials}

The S\&T Ranch Simulation game is available to the public and can be downloaded from the website of the Western Center for Integrated Resource Management. ${ }^{i}$ We're currently writing a scenario guide and manual, but these are not currently available. Past presentations and workshop materials can be found on the website.

\section{Acknowledgments}

The authors gratefully acknowledge the support of the Colorado State University Agricultural Experiment Station and CSU Extension in developing the STM workshop and the S\&T Ranch game.

\section{References}

1. Ritten, J., M. Gimenez, E. Karchergis, W. Hibbs and J. Pritchett. 2011. Linked ecological and economic state and transition model for adaptive management of rangeland ecosystems. Paper presented at the joint annual meeting of the Canadian Agricultural Economics Society and the Western Agriculture Economics Association; 30 June 2011; Banff, AB, Canada.

2. Kelley, W. 2011. Rangeland managers' adoption of innovations, awareness of state and transition models, and management of Bromus tectorum, a survey of ranchers and natural resource professionals in Wyoming and Colorado [MS thesis]. Fort Collins, CO, USA: Colorado State University. 273 p.

3. Rowe, H. I., and E. T. Bartlett. 2001. Development and federal grazing policy impacts on two Colorado counties: a comparative study. In: L. A. Torell, E. T. Bartlett, and R. Larranaga [EDs.]. Current issues in rangeland resource economics. Proceedings of a symposium sponsored by Western Coordinating Committee 55 (WCC-55); 17-23 February 2001; New Mexico State University, Las Cruces, NM, USA. Las Cruces, NM, USA: New Mexico State University. Research Report 737. p. 100-110.

4. The Farm Level Income and Policy Stimulator Model [FLIPSIM]. 2012. College Station, TX, USA: The Agricultural and Food Policy Center, Texas A\&M University. Available at: http:// www.afpc.tamu.edu/models/flipsim/. Accessed 21 February 2012.

\footnotetext{
'To download the S\&T Ranch Simulation game, see http://www.wcirm. colostate.edu/events/petry.html.
} 
5. Kachergis, E. 2011. An alternate state approach to range management in the sagebrush steppe [dissertation]. Fort Collins, CO, USA: Colorado State University. 195 p.

6. Knapp, C. N., M. E. Fernandez-Gimenez, E. Kachergis, and A. Rudeen. 2011. Evaluation and integration of local knowledge and ecological data-driven state-and-transition models. Rangeland Ecology \& Management 64:158-170.

7. Kachergis, E., M. E. Fernandez-Gimenez, and M. E. RoccA. 2012. Differences in species composition as evidence of alternate states in the sagebrush steppe. Rangeland Ecology $\mathcal{E}^{\circ}$ Management (in press).

8. Pellant, M., P. Shaver, D. A. Pyke, and J. E. Herrick. 2005. Interpreting indicators of rangeland health. Version 4. Denver, CO, USA: US Department of the Interior-Bureau of Land Management National Science and Technology Center. Technical Reference 1734-6. $122 \mathrm{p}$.
Authors are Associate Professor, Colorado State University, Fort Collins, CO 80523,USA,James.Pritchett@ColoState.edu (Pritchett); Postdoctoral Research Ecologist, USDA-ARS Rangeland Resources Research Unit, Cheyenne, WY 82009, USA (Kachergis); Codirector, Western Center for Integrated Resource Management, and Special Appointment Assistant Professor, Dept of Agriculture and Resource Economics, Colorado State University, Fort Collins, CO 80523, USA (Parsons); Associate Professor, Dept of Forest and Rangeland Stewardship, Colorado State University, Fort Collins, CO 80523, USA (Fernandez-Gimenez); and Assistant Professor, Dept of Agricultural and Applied Economics, University of Wyoming, Laramie, WY 82071, USA (Ritten). The project is supported by USDA-NIFA grant COLO-2008-00725 titled "Linking Ecological and Economic State-and-Transition Models for Adaptive Management of Rangeland Ecosystems."

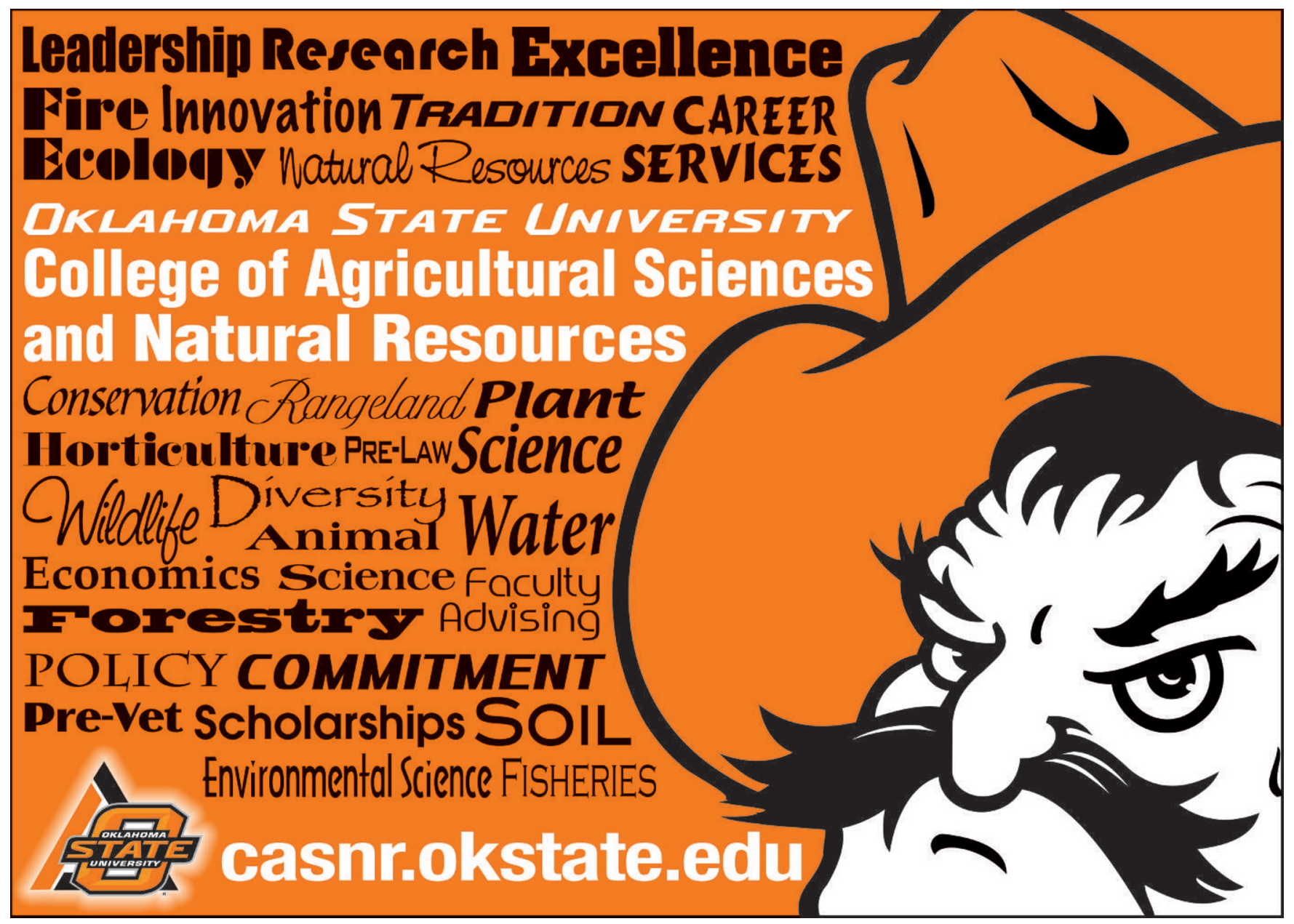




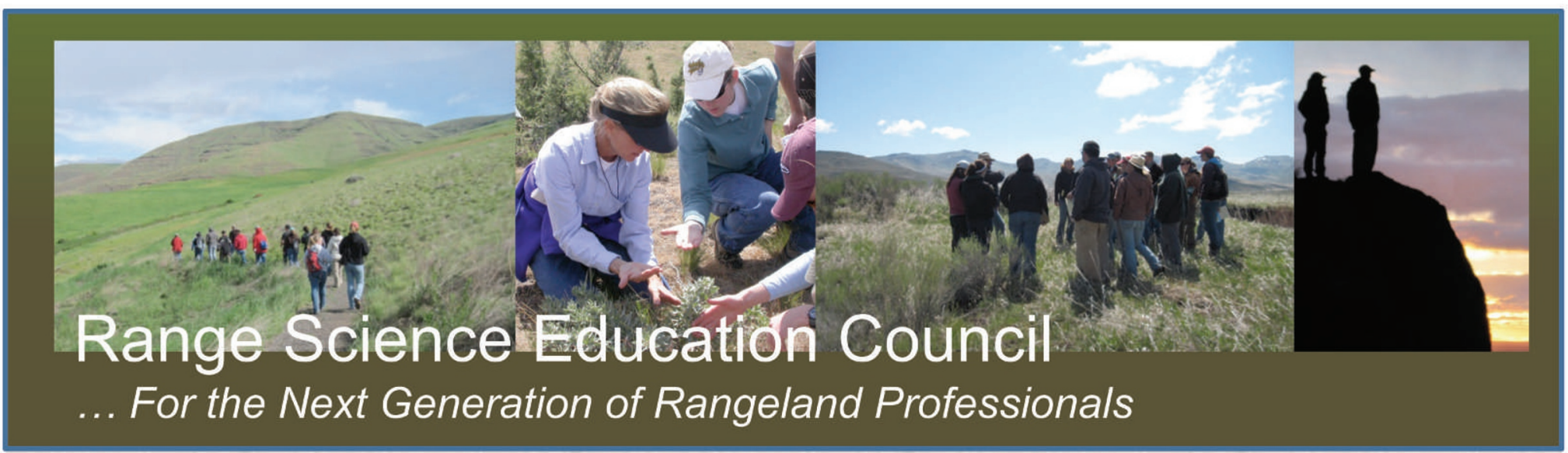

We are representatives from universities and colleges that offer courses and degrees in rangeland ecology and management. Our objectives are to:

- Promote high standards in the teaching of range ecology and management.

- Advance the professional ability of range managers and scientists.

- Provide a medium for the exchange of information and ideas among range faculty.

- Provide a liaison between academic institutions and land management agencies in affairs relating to range education and employment standards.

- Foster wider understanding of the problems of range education.
We meet every year during the Annual Meeting of the Society for Range Management to exchange information about range programs at member institutions and to discuss contemporary issues in rangeland education.

Current activities and projects include:

- Recognize outstanding range educators.

- Organize symposia and workshops on range education and faculty development.

- Develop innovative educational materials and revitalize the undergraduate range curriculum.

For more information, see our webpage at: www.rangelands.org/RSEC/RSEC.htm

Member Institutions: Arizona State University, Brigham Young University, California Polytechnic State University, Chadron State University, Colorado State University, Fort Hays State University, Great Basin College, Humboldt State University, Kansas State University, Montana State University, New Mexico State University, North Dakota State University, Oklahoma State University, Oregon State University, South Dakota State University, Sul Ross State University, Texas A\&M University, Texas Christian University, Texas Tech University, University of Alberta, University of Alaska - Fairbanks, University of Arizona, University of California- Berkeley, University of California - Davis, University of Idaho, University of Nebraska - Lincoln, University of Nevada - Reno, University of Wyoming, University of Queensland - Gatton, Utah State University, Washington State University. 